\title{
Atendimento do apoio escolar a uma aluna com deficiência intelectual de uma escola da rede estadual de ensino do município de Curuçá-PA
}

\author{
School support service to a student with intellectual disabilities from a school in the state education \\ network in the municipality of Curuçá-PA
}

Servicio de apoyo escolar a un alumno con discapacidad intelectual de una escuela de la red estatal de educación en el municipio de Curuçá-PA

\begin{abstract}
Resumo
O presente estudo objetiva analisar o atendimento do apoio escolar oferecido a uma aluna com deficiência intelectual de uma escola pública estadual do Pará, localizada no município de Curuçá. A discussão teórica está orientada segundo a Constituição Brasileira de 1988, abordando os fundamentos históricos e políticos da Educação Especial e os estudos acerca da Deficiência Intelectual, revelando-se a importância de um sistema escolar inclusivo que tenha um olhar sensível às necessidades desse público no processo de escolarização. Nossa compreensão do assunto é que para uma efetiva implementação da proposta de educação inclusiva, não basta ampliar o acesso do público da educação especial nas escolas comuns, é necessário investir na qualificação docente, em uma equipe multidisciplinar para o atendimento desses alunos, e rever junto aos outros sujeitos envolvidos no processo educacional escolar, práticas de intervenção pedagógica na educação especial. O levantamento dos dados foi realizado com base em observações e aplicação de atividades desenvolvidas com auxílio de recursos pedagógicos adaptados. Destacam-se como resultados da análise, a falta de planejamento de um trabalho docente direcionado as necessidades educacionais da aluna, as contribuições dos recursos pedagógicos adaptados para diminuir as barreiras encontradas no processo de escolarização da aluna e ampliar sua capacidade de aprendizagem, indicando-se avanços tanto no aspecto pedagógico quanto social. Vinculado à abordagem qualitativa, o estudo realizou-se por meio da pesquisa de campo de caráter exploratório em uma escola da zona rural da rede estadual de ensino, localizada em Curuçá-PA.
\end{abstract}

Palavras-chave: Educação especial; Deficiência intelectual; Apoio escolar; Recursos adaptados.

\begin{abstract}
The present study aims to analyze the attendance of school support offered to a student with intellectual disabilities from a state public school in Pará, located in the municipality of Curuçá. The theoretical discussion is guided by the Brazilian Constitution of 1988, approaching the historical and political foundations of Special Education and studies on Intellectual Disability, revealing the importance of an inclusive school system that has a sensitive look at the needs of this public in the process. of schooling. Our understanding of the subject is that for an effective implementation of the inclusive education proposal, it is not enough to expand the access of the public to special education in common schools, it is necessary to invest in teacher qualification, in a multidisciplinary team to assist these students, and to review together to the other subjects involved in the school educational process, pedagogical intervention practices in special education. Data collection was carried out based on observations and application of activities developed with the help of adapted pedagogical resources. As results of the analysis, the lack of planning of a teaching work directed to the educational needs of the student, the contributions of the pedagogical resources adapted to reduce the barriers
\end{abstract}


encountered in the student's schooling process and expand her learning capacity, stand out. advances both in the pedagogical and social aspects. Linked to the qualitative approach, the study was carried out through field research of an exploratory nature in a school in the rural area of the state education network, located in Curuçá-PA.

Keywords: Special education; Intellectual disability; School support; Adapted resources.

\section{Resumen}

El presente estudio tiene como objetivo analizar la asistencia al apoyo escolar ofrecido a un alumno con discapacidad intelectual de una escuela pública estadual de Pará, ubicada en el municipio de Curuçá. La discusión teórica se guía por la Constitución brasileña de 1988, abordando los fundamentos históricos y políticos de la Educación Especial y los estudios sobre Discapacidad Intelectual, revelando la importancia de un sistema escolar inclusivo que tenga una mirada sensible a las necesidades de este público en el proceso. de la escolarización Nuestro entendimiento del tema es que para una implementación efectiva de la propuesta de educación inclusiva, no es suficiente ampliar el acceso del público a la educación especial en las escuelas comunes, es necesario invertir en la calificación de los docentes, en un equipo multidisciplinario para asistir estos estudiantes, y revisar junto a los demás sujetos involucrados en el proceso educativo escolar, prácticas de intervención pedagógica en educación especial. La recolección de datos se realizó a partir de observaciones y aplicación de actividades desarrolladas con la ayuda de recursos pedagógicos adaptados. Como resultados del análisis se destacan la falta de planificación de una labor docente dirigida a las necesidades educativas del estudiante, los aportes de los recursos pedagógicos adecuados para reducir las barreras encontradas en el proceso de escolarización del estudiante y ampliar su capacidad de aprendizaje. tanto en el aspecto pedagógico como social. Vinculado al enfoque cualitativo, el estudio fue realizado a través de una investigación de campo de carácter exploratorio en una escuela del área rural de la red estatal de educación, ubicada en Curuçá-PA.

Palabras clave: Educación especial; Discapacidad intelectual; Apoyo escolar; Recursos adaptados.

\section{Introduçãa}

$\mathrm{O}$ atendimento educacional as pessoas com deficiência tem sido alvo de muitas pesquisas no âmbito da educação inclusiva, tais estudos contribuem para reafirmar o direito de todos à educação independente de sua condição física, social, religiosa, política ou de gênero (Mendes, 2001, Werneck, 2006; Magalhães et al., 2021). No Brasil a educação é garantida nos principais documentos legais como um direito comum a todos, e um dos públicos da educação que vem se tornando cada vez mais presente nos ambientes escolares e chamando a atenção das entidades e profissionais envolvidos nesse processo não somente educacional, mas inclusivo, é das pessoas com deficiência (Smith, 2008; Mendes \& Almeida, 2010; Barbos \& Bezerra, 2021).

Deste modo, este estudo trata-se de uma pesquisa sob a temática da Educação Especial, que se constitui com base no atendimento do apoio escolar a uma aluna com deficiência intelectual de uma escola rede estadual de ensino localizada no município de Curuçá-PA.

Toda mobilização pela Educação Inclusiva é uma ação não somente pedagógica, mas política, cultural e, principalmente, social (Brasil, 2008; Griboski et al., 2008; Capellini \& Rodrigues, 2014). Neste sentido, a relevância social deste estudo está articulada em defesa do direito de todos os alunos de aprender e participar do processo educacional, sem qualquer tipo de discriminação, bem como está descrito no documento da Declaração de Salamanca de 1994, sobre Princípios, Políticas e Práticas na Área das Necessidades Educativas Especiais, a qual estabelece o princípio fundamental da escola inclusiva: o direito de todas as pessoas à igualdade, e das crianças, incluindo aquelas com "necessidades educacionais especiais", ao acesso à escola regular, com educação gratuita e de qualidade (Brasil, 1994; Estobaüs \& Mosquera, 2006).

A construção deste estudo também está vinculada a sua relevância científica no sentido do compromisso com o avanço educacional das pessoas com deficiência, produzindo conhecimentos que contribuam para o processo de universalização do acesso à escola e garantam um sistema educacional inclusivo, de modo que não somente abra as portas das escolas para estes alunos, mas os possibilite um ensino de qualidade, com recursos e profissionais que atendam suas especificidades educacionais (Brasil, 2008; Griboski et al., 2008). Corroborando para os estudos na área da educação inclusiva, no que tange o trabalho desenvolvido pelo apoio escolar da educação especial, voltado ao atendimento as pessoas com deficiência intelectual. 
Vale ressaltar a importância deste estudo ao pedagogo enquanto profissional apto a trabalhar na educação especial, bem como no auxílio e no atendimento educacional especializado de alunos com deficiência, por apresentar informações referentes às ações a serem desempenhadas por estes profissionais para as práticas no contexto escolar inclusivo.

A partir deste ponto de partida, buscou-se saber: Como tem se dado o atendimento do apoio escolar a uma aluna com deficiência intelectual de uma escola da zona rural da rede estadual de ensino do município de Curuçá-PA? Assim, este trabalho teve como objetivo analisar o atendimento do apoio escolar a uma aluna com deficiência intelectual de uma escola da zona rural da rede estadual de ensino do município de Curuçá-PA.

\section{Metodologia}

O presente estudo está vinculado à abordagem qualitativa e se caracteriza como uma pesquisa de campo de caráter exploratório, a fim de construir experiências diretas com a situação de estudo. Para Creswell (2007) esse tipo de abordagem busca explorar e entender os fenômenos a partir dos símbolos ou significados atribuídos a eles. O processo da pesquisa envolve objetividade para dar conta das questões que surgem no ambiente do participante, uso de técnicas adequadas para a coleta de dados e a análise subjetiva feita pelo pesquisador, expondo suas interpretações acerca da relação dos significados dados ao fenômeno para os indivíduos e a sociedade.

Considerou-se a pesquisa de campo como meio de investigação, pela necessidade de o pesquisador estar próximo do seu objeto de estudo, facilitando para que a análise e interpretação dos dados estejam em maior consonância com os dados coletados. Para Gil (2002) esse tipo de pesquisa exige que o pesquisador permaneça o maior tempo possível no ambiente, conhecendo a fundo a realidade, assim é possível entender os costumes, as regras e as regularidades do grupo estudado.

A pesquisa foi realizada em uma escola localizada na zona rural do município de Curuçá, que é administrada pelas esferas Estadual e Municipal, oferecendo as modalidades de ensino fundamental, educação de jovens e adultos e Educação Especial.

\subsection{Participantes}

A pesquisa foi realizada com uma aluna com deficiência intelectual (Síndrome de Down), de 28 anos de idade e que cursava o oitavo ano do ensino fundamental. A aluna iniciou os estudos na escola em que a pesquisa foi realizada, no ano de 2016, quando foi matriculada no sexto ano do ensino fundamental do ensino regular.

Recebeu Atendimento Educacional Especializado durante todo o período em que esteve matriculada na escola, ou seja, desde 2016 até o ano de 2019. Seu atendimento é realizado no mesmo turno das aulas no ensino regular pelo fato de residir em uma localidade distante da escola e necessitar de transporte escolar, que passa somente no turno da manhã.

\subsection{Procedimentos}

Os procedimentos metodológicos que guiaram esta pesquisa de campo correspondem ao levantamento com base nas informações e relados prestados pela professora de AEE, na documentação da aluna e nas observações realizadas no ambiente do participante. Esta coleta de dados teve o propósito inicial de conhecer as práticas educativas desenvolvidas no contexto escolar da aluna e as barreiras encontradas nesse processo.

Para esse tipo de pesquisa, Minayo (2008) destaca que o mais importante é a objetivação, pois durante a investigação é necessário reconhecer os nuances do fenômeno estudado, rever as teorias sobre o tema, determinar conceitos e concepções relevantes, usar técnicas de coleta de dados adequadas, e finalizar com a análise sistemática e contextualizada de todo o material içado. 
Desta forma, a observação constitui-se como elemento principal desta pesquisa, influenciando desde a formulação do problema, até a coleta, análise e interpretações dos dados, assim tornou-se mais evidente a compreensão da rotina escolar da aluna. Gil (2008) destaca que a principal vantagem da observação em ralação às outras técnicas é que os fatos são percebidos diretamente, o contato do pesquisador com o objeto é real e prático, o que pode reduzir a subjetividade que decorre todo o processo de investigação social. Sobre a desvantagem, o autor citado acima, considera que a presença do pesquisador pode alterar o comportamento do participante, interferindo na espontaneidade dos mesmos, consequentemente nos resultados que podem se tornar pouco confiáveis.

As observações foram realizadas nos locais onde eram desenvolvidas as atividades com a aluna, na sala de ensino regular, na Sala de Recursos Multifuncionais (SRM) e nos intervalos, a mesma ocorreu no final do período escolar de 2017, duas vezes na semana, quatro horas por dia.

Posteriormente, buscou-se materiais disponíveis na escola adaptando-os para potencializar a aprendizagem da aluna. O último passo foi a utilização dos recursos adaptados, alguns foram usados como auxílio nas aulas de português e matemática, cada recurso foi utilizado mais de uma vez, que variou de acordo com a necessidade da aula. As barreiras e os avanços foram registrados por meio de anotações e fotografias, para auxiliar na análise e discussão dos dados obtidos na pesquisa.

\section{Resultados e Discussão}

Os resultados desta pesquisa serão apresentados por meio da descrição dos dados observados acerca do atendimento realizado com a aluna com deficiência intelectual, que também serão demonstrados através de um quadro contendo as principais informações levantadas, onde identificou-se as principais barreiras no processo de aprendizagem da aluna e os seus progressos, após a utilização das atividades adaptadas. Os dados serão discutidos com base na relação entre o que foi levantado na pesquisa de campo e o que o referencial teórico consultado relata a respeito desse tópico.

Inicialmente observou-se com relação ao comportamento da aluna, uma pessoa carinhosa, que apesar de sua timidez relacionava-se muito bem com as pessoas que se aproximavam dela, sempre muito prestativa. A timidez interferia na sua comunicação, não gostava de se expressar em público, e não tinha amigos na sua turma do ensino regular, tentava ficar sempre mais próxima das professoras do AEE, também demonstrava uma afeição muito grande pelo diretor da escola.

Geralmente, nas escolas da zona rural a maioria dos alunos reside distante do local da escola, e por isso dependem do transporte escolar, este era o caso da aluna. Ela morava em uma comunidade que ficava a aproximadamente $10 \mathrm{~km}$ de distância da escola e utilizava o transporte escolar com autonomia. Normalmente, o ônibus passava bem cedo para pegar os estudantes, pois eram de localidades diferentes, assim, chegavam cedo na escola, antes dos professores.

Na primeira semana de observação percebeu-se que ela não estava frequentando a sala regular, ficava esperando a professora do AEE chegar, para poder ficar na Sala de Recursos Multifuncionais, onde passava a maior parte do tempo, mesmo quando não era seu dia de atendimento, que não acontecia no contraturno, pelo fato de não haver transporte escolar no período da tarde e pela professora do AEE ser lotada somente com 100 horas, atuando apenas no turno da manhã.

Nos aspectos sociais, de organização e autocuidado, a estudante era muito responsável e cuidadosa com seu material escolar e consigo mesma, dificilmente faltava as aulas, a não ser por algum problema de saúde, tinha autonomia para merendar e fazer a higiene pessoal, algumas vezes ficava com vergonha de pegar a merenda ou repetir, então pedia para que a atuante no apoio escolar fosse pegar para ela, buscando desenvolver cada vez mais a autonomia da aluna, a professora do apoio lhe acompanhava até a copa, e com jeito fazia com a própria aluna pedisse ser lanche conseguia fazer a própria aluna pedir o lanche.

Com relação ao desenvolvimento escolar, preocupou-se, a priori, em identificar suas maiores barreiras no processo de ensino e aprendizagem, a fim de planejar atividades que atendessem de fato suas necessidades. 
A aluna apresentava dificuldades na dicção e pronúncia de palavras, sua fala era comprometida, com uma leve gagueira, baixo tom de voz, tinha limitações ao pronunciar palavras complexas, fazendo trocas e omissões de fonemas, ela conhecia poucas letras do alfabeto e não desenvolveu consciência fonológica, esquecia com facilidade o que the era ensinado e devido ao seu desenvolvimento cognitivo lento tinha dificuldade em compreender contextos apenas no campo das ideias, precisava sempre de auxílio de material concreto. Ela também apresentava dificuldades em manter a concentração, se dispersava com facilidade, conseguia memorizar melhor de forma visual do que de forma auditiva. Seu maior interesse era pelas atividades que envolviam pintura, recorte, textos com imagens, desenho, vídeo, música e dança.

Nas atividades que estimulavam a coordenação motora fina; recorte, colagem, desenho, pintura, a aluna precisava apenas de orientações, tinha autonomia na realização; fazia cópias, mas de forma aleatória, a menos que se ficasse indicando cada letra a ser copiada; quando solicitada a copiar do quadro, também escrevia letras e símbolos aleatórios; ainda tinha dificuldade em diferenciar direção, posição, como, em cima/embaixo, em frente/ atrás, primeiro/último.

Nas atividades que envolviam percepção, atenção e concentração, reconhecia cores primárias e algumas secundárias; reconhecia alguns números, mas ainda confundia; reconhecia seu nome pela letra inicial; desenhava, possui traços característicos, seus desenhos de pessoas, árvores e animais são sempre retratados do mesmo jeito; quando pintava não obedecia a margem do desenho, mas preenchia todo o espaço. Com relação às atividades lógico matemáticas relacionava número à quantidade, até 3; fazia contagem, nem sempre na sequência correta até 10.

A aluna precisava de apoio com instruções na realização de todas as atividades pedagógicas. Nas atividades que envolviam cálculo matemático simples; identificação e escrita de números, de algumas letras e palavras; conceitos relacionados às disciplinas de CFB (Ciências Físicas e Biológicas), história e geografia como: meio ambiente, saúde, cidadania, sistema solar, território brasileiro, precisava de apoio de materiais concretos, bem como adaptações de recursos para mediar a aprendizagem.

Observando a rotina em sala de aula, bem como as atividades propostas para a aluna, percebeu-se que a falta de planejamento dos professores era uma das barreiras no processo de ensino/aprendizagem da aluna. Por fazer parte de uma turma das séries finais do ensino fundamental, ela tinha em média, aula de três disciplinas por dia, alguns docentes, como das disciplinas de língua portuguesa, CFB, artes, levavam atividades que correspondiam as suas especificidades, essas atividades eram, geralmente, impressas ou copiadas no caderno da aluna.

Em língua portuguesa, conteúdos como produção de texto, classe das palavras, a professora trabalhava com imagens, no momento da realização da atividade, com mediação do apoio escolar, a aluna conseguia desenvolver um texto coerente utilizando as imagens e destacar o adjetivo e o verbo contidos no texto. Em CFB, a professora também utilizava imagens para demonstrar os conteúdos como o corpo humano, sistemas, células, a aluna identificava partes do corpo humano, a posição do coração, quando se trabalhavam as células, era um pouco mais difícil a compreensão, por exemplo, explicava-se o que era a célula e eram dados exemplos de seres uni e pluricelulares, no momento da atividade a aluna não conseguia identificar com autonomia as imagens de seres que possuíam somente uma célula e os que possuíam mais de uma. Em artes, quando se solicitava que a aluna desenhasse algo, ela sempre retratava pessoas, tentava fazer uma casa, árvore, e seus traços têm uma característica própria, inconfundíveis, então, para trabalhar a percepção, atenção e ampliar as formas de desenho da aluna, o professor trabalha a releitura, expondo obras com diferentes traços, para a aluna se inspirar e criar sua própria pintura. Ela não compreende o conceito de releitura, pois é subjetivo, mas realiza as atividades propostas pelo professor, que não são específicas para ela, toda a turma produz esses trabalhos.

No entanto, outros professores não levavam, então passavam atividades, por exemplo, de copiar seu nome, desenhar, pintar, que muitas vezes não tinham relação com o conteúdo, com a disciplina e nem seguia um critério de avaliação por meio do currículo funcional, Brasil (2008) obriga os sistemas de ensino a assegurar aos alunos, currículo, métodos, recursos e 
organização específicos para atender às suas necessidades, portanto, o ensino oferecido a eles deve ser pensado de modo a desenvolver sua capacidade de aprendizagem, para isso, os profissionais envolvidos neste ensino, precisam buscar destacar suas potencialidades, realizando avaliações do seu desenvolvimento e formulando ações que estimulem a aprendizagem e autonomia desses alunos (Sassaki, 2006; Millan et al., 2015).

Com base nas observações, em que se pode conhecer a rotina da aluna dentro e fora da sala de aula, a primeira ação foi então de conversar com a aluna, convidando-a para participar das aulas na sua turma do ensino regular, mesmo com certa resistência, aceitava ir, em sala demostrava sempre muita timidez e desconforto, notou-se que ela ainda estava se adaptando aquele ambiente, pois ainda não se sentia a vontade. Entende-se que o fato de ter uma pessoa como apoio escolar mediando seu processo educacional, que lhe acompanhava em sala e em outros ambientes da escola, a fez ficar mais confortável, principalmente em sala, com o tempo ela foi fazendo novas amizades na turma e desenvolvendo mais autonomia para permanecer na sala mesmo quando o apoio não estava.

Neste sentido, os estudos de Schwartzman e Lederman (2017) apontam uma discordância ao modelo de inclusão em que crianças, com diferentes tipos de deficiências, são incluídas em classes regulares, com a presença de uma auxiliar ou tutora, pois questionam que essa inclusão acaba por segregar o aluno dentro da sala de aula, por mostrar que ele é o único que necessita de atenção especial, mas apoiam como uma alternativa para a educação inclusiva, uma prática já adotada em algumas instituições de ensino, na qual estudantes com necessidades educacionais frequentam classes regulares apenas o que está sendo ensino aos à turma é do interesse deles e está ao alcance da sua compreensão, e ainda é oferecido a esses alunos um ambiente pedagógico diferente, dentro da escola, tendo assistência individual e especializada.

Posteriormente, planejaram-se algumas atividades com materiais da escola e recursos adaptados de acordo com as especificidades da aluna com deficiência intelectual (Quadro 1). 
Quadro 1: Barreiras e problemas identificados, e os materiais adaptados para inclusão do aluno com deficiência intelectual.

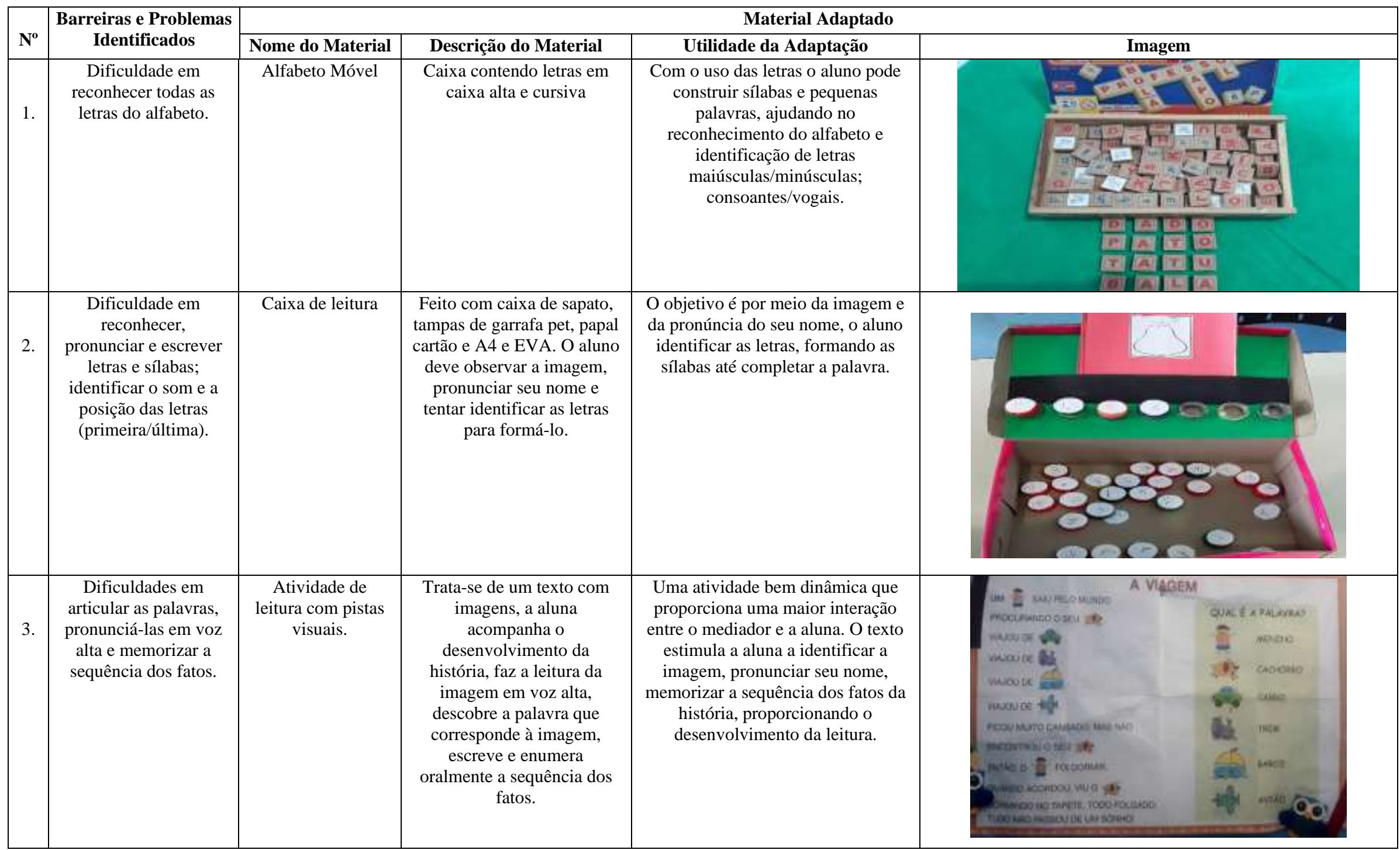


Research, Society and Development, v. 11, n. 2, e9411225677, 2022

(CC BY 4.0) | ISSN 2525-3409 | DOI: http://dx.doi.org/10.33448/rsd-v11i2.25677

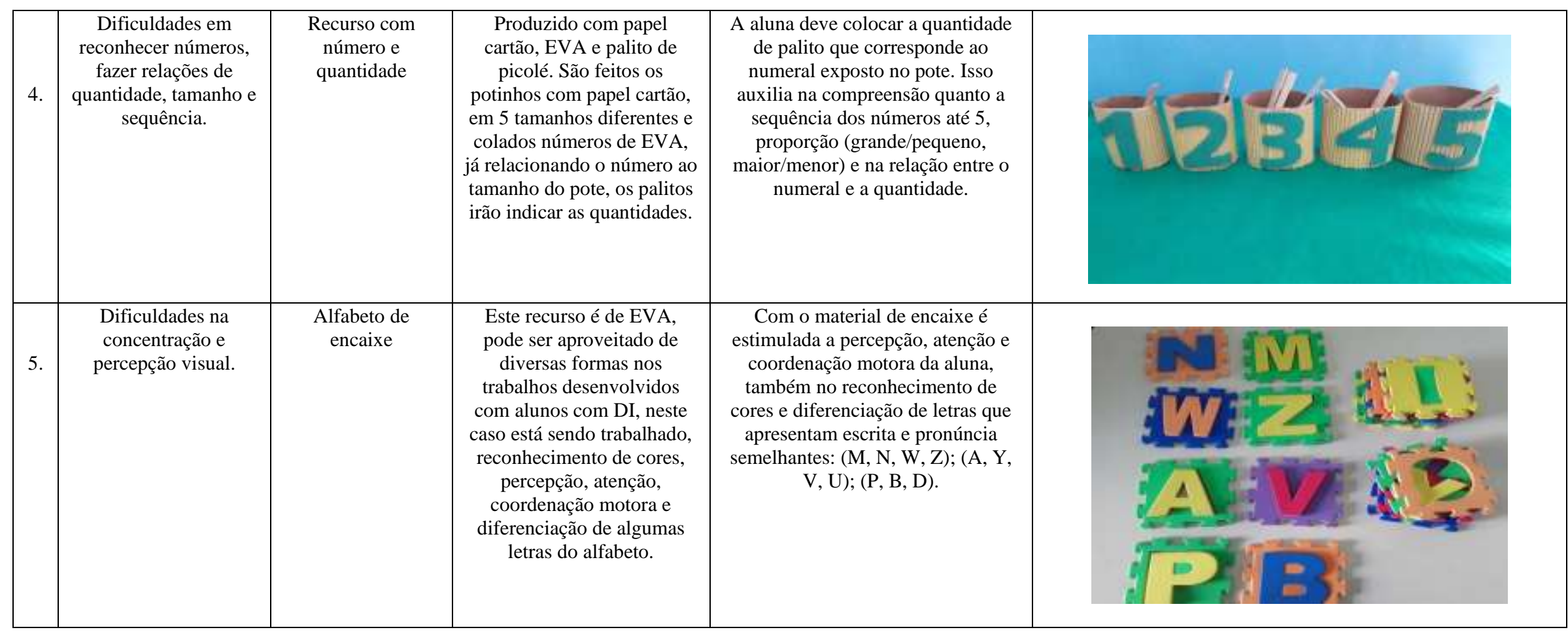

Fonte: Monteiro (2022). 
Os materiais foram adaptados com o intuito de atingir as especificidades educacionais da aluna, propondo-se atividades que de forma interativa iriam contribuir não somente para o desenvolvimento de suas funcionalidades, mas para trabalhar temas referentes às disciplinas de língua portuguesa e matemática, de acordo com seu nível de comprometimento cognitivo. Desta forma, os objetivos específicos da pesquisa consistem em descrever a realização das atividades, verificando os progressos após a utilização e as barreiras ainda existentes no processo de ensino e aprendizagem da aluna.

Durante o estudo notou-se que a aluna não reconhecia todas as letras do alfabeto, portanto, propôs-se o uso do alfabeto em recurso visual e móvel para que ela conseguisse compreender o sistema de símbolos de escrita da língua portuguesa, conforme mostra a imagem da linha um do quadro 1 (Alfabeto Móvel).

Tendo em vista as dificuldades em reconhecer, pronunciar e escrever sílabas utilizou-se a caixa de leitura. Nesta atividade, para chamar a atenção e ajudar a relacionar o som à escrita da letra, usou-se além das letras que foram escritas pela aluna com o auxílio do Alfabeto móvel, imagens de objetos, frutas e animais. A aluna identificava a imagem, pronunciava seu nome e tentava identificar a letra ou silaba inicial da palavra, assim, as figuras ajudavam a aluna a conhecer as sílabas, facilitando a formação das palavras, como se observa na imagem da linha dois do Quadro 1 (Caixa de Leitura).

Para as barreiras com relação à pronúncia das palavras, compreensão de sequência lógica, realizou-se a atividade de leitura com pistas visuais. Esse recurso foi utilizado para que a aluna interpretasse, oralmente, textos simples com imagens, estimulando a percepção e a memória quanto ao desenvolvimento da história e a sequência lógica dos fatos. Também contribuía para a escrita, pois a aluna escrevia os nomes das imagens no caderno, e para a dicção, já que era estimulada a pronunciar as frases do texto, tal atividade pode ser observada na imagem da linha três do Quadro 1 (Atividade de Leitura com Pistas Visuais).

Estas três atividades foram complementares, buscando-se avanços na capacidade de leitura e aquisição da linguagem escrita. Millan; Spinazola e Orlando (2015) sugerem que ao realizar uma atividade com alunos com deficiência intelectual, deve-se utilizar instruções curtas e objetivas, explicando a atividade em pequenos passos.

Após a aplicação destas atividades, a aluna ampliou o uso do alfabeto, passou a identificar e escrever as vogais, tem mais facilidade em reconhecer e escrever a letra em caixa alta. Ao final da pesquisa a aluna ampliou o reconhecimento do alfabeto, identificando as letras (A, B, C, D, E, H, I, M, N, O, P, R, S, T, U, V e X). Também passou a identificar e escrever quase todas as letras do seu nome, ainda consegue diferenciá-lo pela letra inicial, durante a realização da atividade com a caixa de leitura, a aluna conseguiu construir sílabas e pequenas palavras, que eram compostas por letras que ela conhecia. A aluna ainda apresenta barreiras para reconhecer as posições das letras e fonemas na constituição de uma palavra, portanto tem dificuldade em avançar para a hipótese silábica.

Como a aluna apresentava dificuldades em relacionar números às quantidades acima de 3 , e realizava contagem, nem sempre na sequência correta, até 10 , utilizou-se a sequência de 1 a 5, com auxílio de material para facilitar a identificação dos números e relacioná-los às quantidades correspondentes. Na atividade com números e quantidades, como demonstrado na imagem da linha quatro do Quadro 1 (Recurso com número e quantidade), os potes foram criados em tamanhos diferentes, conforme vai aumentando o tamanho do pote, aumenta-se a quantidade de palitos a serem colocados nos mesmos, seguindo a sequência de 1 a 5 , isso ajudou a aluna a identificar os números e escrevê-los. Ainda apresenta dificuldades em relacionar alguns, esse resultado oscila, algumas vezes consegue até 5 , outras até 3 .

Para as dificuldades na concentração e percepção visual observadas da aluna, adotou-se o uso do material apresentado na imagem da linha cinco do Quadro 1 (Material de Encaixe), além das dificuldades acima citadas, a aluna confundia no momento de escrever ou indicar as letras que têm símbolos de escrita e sons semelhantes, como (M, N, W, Z); (A, Y, V, U); (P, B, D, T). Após a realização da atividade, aplicada mais de uma vez, passou a diferenciar as letras (P, B, D e T); (M; N); (A; $\mathrm{V})$, ainda confunde ( $\mathrm{M}$ com $\mathrm{W})$; ( $\mathrm{V}$ com $\mathrm{U}), \mathrm{o}(\mathrm{Z}$ e $\mathrm{Y})$ não reconhece, mas usa para representar outras letras, como ( $\mathrm{V}$ e U). 
Com relação a atenção, tem dificuldade em concentrar-se por muito tempo em cada atividade, essa é uma característica da DI, que dificulta o rendimento da aprendizagem dos alunos.

A utilização das atividades e algumas atitudes do apoio escolar, como estar presente na sala de ensino regular, estimulando a interação da aluna com a turma, contribuíram para diminuir as barreiras encontradas no processo de escolarização da aluna e ampliar sua capacidade de aprendizagem, o principal objetivo do apoio escolar consiste em estimular a autonomia da aluna, corroborando com o que sugerem Millan et al. (2015): durante a realização de atividades com os alunos com deficiência intelectual é importante oferecer apoio a eles, por meio de estratégias de pequenos grupos ou parceria com um aluno, isso favorece a interação social desses alunos com os seus pares, esse apoio também pode ser de um adulto, porém, recomenda-se que esse apoio seja retirado aos poucos, visando uma maior autonomia do aluno.

Assim, o apoio oferecido à aluna proporcionou um maior desenvolvimento de sua habilidade socioafetiva, agora, ela interage muito bem com todos da escola, uma vez que a educação escolar inclusiva não deve se limitar apenas ao aspecto didático-pedagógico, a inclusão nas escolas também depende do fator socioafetivo. Os alunos devem sentir-se acolhidos e perceber que a diversidade não representa uma barreira e sim um estímulo para desenvolver a consciência de todos os envolvidos no processo educacional (Brasil, 2002, Mazzotta, 2010, Fernandes, 2010; Magalhães et al., 2021).

O país vive um processo ativo de inclusão social e escolar, mas embora muito se tenha avançado com relação ao direito das pessoas com deficiência a participarem de um sistema geral de ensino, que reconhecesse e atendesse suas especificidades educacionais, ainda há muitos desafios a superar para que se alcance integralmente o objetivo da escola inclusiva, garantida nos principais documentos que tangem o atendimento educacional ao público alvo da Educação Especial, como: a Constituição Federal de 1988, LDB de 1996 (Brasil, 1996), o Decreto no 3.298 de 1999 (Brasil, 1999), a Política Nacional de Educação Especial (Brasil, 2008) e a lei de nº 13.146 de 2015.

\section{Conclusão}

A partir das observações acerca do atendimento educacional oferecido a uma aluna com deficiência intelectual em uma turma regular de ensino, pôde-se conhecer seus pormenores, seus comportamentos e as práticas pedagógicas desenvolvidas para ela, visando sua inclusão socioeducacional. Foi importante conhecer a aluna, identificar suas dificuldades no processo de ensino e aprendizagem, as habilidades já desenvolvidas e as que ainda precisavam ser trabalhadas, para propor atividades capazes de estimular suas potenciais habilidades, e assim, chegar aos resultados da pesquisa.

Ao analisar as respostas da aluna após o uso dos recursos adaptados, notou-se a importância, destes, para facilitar a alunos com DI maior compreensão no momento de realizar uma atividade. Desta forma, constatou-se que diante das contribuições do apoio oferecido, bem como o uso dos materiais adaptados, a aluna teve avanços nas áreas que as atividades abrangiam, ampliando-se o conhecimento do sistema de escrita da língua portuguesa e o processo de aquisição da linguagem escrita, maior concentração nas atividades, capacidade de interpretação e na interação social.

As pesquisas e discussões apresentadas no âmbito da educação especial inclusiva e especialmente do ensino proporcionado a alunos com deficiência intelectual contribuem para que as especificidades desses alunos sejam respeitas, buscando-se um ensino direcionado, conforme as respostas dadas pelos alunos durante o estudo individualizado. Para tanto, destaca-se a necessidade de um trabalho colaborativo, entre a gestão escolar, professor de sala regular, professor da educação especial, a família e os demais profissionais envolvidos neste ensino, o que permite avaliar o desenvolvimento e trocar informações que contribuam para o planejamento de ações que promovam desenvolvimento e autonomia desses alunos. 
Research, Society and Development, v. 11, n. 2, e9411225677, 2022

(CC BY 4.0) | ISSN 2525-3409 | DOI: http://dx.doi.org/10.33448/rsd-v11i2.25677

\section{Referências}

Barbosa, A. K. G., \& Bezerra, T. M. C. (2021). Educação Inclusiva: reflexões sobre a escola e a formação docente. Ensino em Perspectivas, 2 (2), 1-11.

Brasil, S. F. (1988). Constituição da república federativa do Brasil. Brasília: Senado Federal, Centro Gráfico.

Brasil (1994). Declaração de Salamanca e linha de ação sobre necessidades educativas especiais. Brasília: UNESCO.

Brasil, L. D. D., \& de Diretrizes, L. (1996). Bases da Educação Nacional-Lei 9.394/96. Brasília, DF.

Brasil (1999). Ministério da Educação. Secretaria de Educação Especial. Decreto no 3.298, de 20 de dezembro de 1999.

Brasil (2008). Ministério da Educação. Política Nacional de Educação Especial na Perspectiva da Educação Inclusiva. MEC/SEESP.

Brasil (2002). Secretaria de Educação Especial. Portal de Ajudas Técnicas para a Educação: Equipamento e Material Pedagógico para Educação, Capacitação e Recreação da Pessoa com Deficiência Física. MEC/SEESP.

Capellini, V. L., \& Rodrigues, O. M. (2014). Fundamentos históricos e legais da educação da pessoa com deficiência, transtorno global do desenvolvimento e altas habilidades/superdotação no Brasil. Historical and legal foundations of the education of people with disabilities, developmental disorder and high skills/giftedness in Brazil] (Bauru: UNESP, 2014);

Creswell, J. W. (2007). Projeto de Pesquisa: métodos qualitativo, quantitativo e misto. trad. Luciana de Oliveira da Rocha. (2a ed.), Artmed.

Fernandes, E. M. (2010). Da deficiência à funcionalidade: novos paradigmas de avaliação e acompanhamento de pessoas com deficiência mental/intelectual. Das margens ao Centro: perspectivas para as políticas e práticas educacionais no contexto da educação especial inclusiva. Araraquara, SP: Junqueira \& Martins.

Griboski, C. M., Alves, D. D. O., Barbosa, K. A. M., Baptista, C. R., Mantoan, M. T. E., Almeida, M. A., \& Fleith, D. D. S. (2008). Política Nacional de Educação Especial na perspectiva da Educação Inclusiva.

Magalhães, T. C., Díaz-Rodriguez, F. M., Fagundes, D. D. A., dos Santos, M. O. F., Prado-Netto, A., Xará, G. M. S. A., \& de Oliveira Porto, R. S. (2021). Educação inclusiva: autoconceito profissional de professores. Research, Society and Development, 10(11), e248101118719-e248101118719.

Mazzotta, M. D. S. (2010). Inclusão escolar e Educação Especial: das diretrizes à realidade das escolas. Das margens ao centro: perspectivas para as políticas e práticas educacionais no contexto da educação especial inclusiva. Araraquara, SP: Junqueira\&Marin, 79-87.

de Souza Minayo, M. C., \& Deslandes, S. F. (2008). Caminhos do pensamento: epistemologia e método. SciELO-Editora FIOCRUZ.

Mendes, E. G. Raízes históricas da educação inclusiva. Trabalho apresentado em agosto de 2001, durante os Seminários Avançados sobre Educação Inclusiva, ocorrido na UNESP de Marília. mimeo..

Mendes, E. G., \& Almeida, M. A. (2016). Das margens ao centro: perspectivas para as políticas e práticas educacionais no contexto da educação especial inclusiva. Junqueira\&Marin Editores.

Millan, A. E., Spinazola, C. D. C., \& Orlando, R. M. (2015). Deficiência Intelectual: Caracterização e atendimento educacional. Revista Educação, 5(2), 7394.

Mosquera, J. J. M., \& Stobäus, C. D. (2004). Educação Especial: em direção à educação inclusiva. Porto Alegre.GIL, Antônio Carlos. Como elaborar projetos de pesquisa. (4a ed.), Atlas.

Sassaki, R. K. (2006). Questões semânticas sobre as deficiências visual e intelectual na perspectiva inclusiva.

Schwartzman, J. S., \& Lederman, V. R. G. (2017). Deficiência intelectual: causas e importância do diagnóstico e intervenção precoces. Inclusão Social, 10(2).

Smith. D, D. (2008). Introdução à Educação Especial: ensinar em tempos de exclusão.

Werneck, C. (2006). Sociedade inclusiva: Quem cabe no seu TODOS? WVA. 